\title{
Growth promotion in pigs by oxytetracycline coincides with down regulation of serum inflammatory parameters and of hibernation-associated protein HP-27
}

Soler, Laura; Miller, Ingrid; Hummel, Karin; Razzazi-Fazeli, Ebrahim; Jessen, Flemming; Escribano, Damian; Niewold, Theo

\author{
Published in: \\ Electrophoresis \\ Link to article, DOI: \\ 10.1002/elps.201500529 \\ Publication date: \\ 2016 \\ Document Version \\ Peer reviewed version \\ Link back to DTU Orbit
}

Citation (APA):

Soler, L., Miller, I., Hummel, K., Razzazi-Fazeli, E., Jessen, F., Escribano, D., \& Niewold, T. (2016). Growth promotion in pigs by oxytetracycline coincides with down regulation of serum inflammatory parameters and of hibernation-associated protein HP-27. Electrophoresis, 37(10), 1277-1286.

https://doi.org/10.1002/elps.201500529

\section{General rights}

Copyright and moral rights for the publications made accessible in the public portal are retained by the authors and/or other copyright owners and it is a condition of accessing publications that users recognise and abide by the legal requirements associated with these rights.

- Users may download and print one copy of any publication from the public portal for the purpose of private study or research.

- You may not further distribute the material or use it for any profit-making activity or commercial gain

- You may freely distribute the URL identifying the publication in the public portal 
1 Growth promotion in pigs by oxytetracycline coincides with down regulation of

2 serum inflammatory parameters and of hibernation-associated protein HP-27

3

4 Laura Soler ${ }^{1}$, , Ingrid Miller ${ }^{2}$, Karin Hummel $^{3}$, Ebrahim Razzazi-Fazeli ${ }^{3}$, Flemming

5 Jessen $^{4}$, Damian Escribano ${ }^{5}$, Theo Niewold ${ }^{1, *}$

6

$7 \quad 1$ Livestock-Nutrition-Quality Division, Department of Biosystems, Faculty of

8 Biosciences Engineering, KU Leuven, Kasteelpark Arenberg 30, Heverlee 3001,

9 Belgium.

102 Department of Biomedical Sciences, University of Veterinary Medicine,

11 Veterinaerplatz 1, 1210 Vienna, Austria.

$12{ }^{3}$ VetCore Facility for Research, University of Veterinary Medicine, Veterinaerplatz 1, 131210 Vienna, Austria.

$14{ }^{4}$ Division of Industrial Food Research, National Food Institute, Technical University of 15 Denmark, 2800 Kgs. Lyngby, Denmark

$16{ }^{5}$ Interdisciplinary Laboratory of Clinical Analysis, Interlab-UMU, Regional Campus of 17 International Excellence “Campus Mare Nostrum”, University of Murcia, 30100 18 Espinardo, Murcia, Spain

20 *Corresponding author: T.A. Niewold, phone +3216 321560, fax +3216321994 , email

21 theo.niewold@biw.kuleuven.be

22

$23{ }^{*}$ L. Soler is currently working at INRA Val de Loire, Nouzilly, France. 
25 List of abbreviations: $\alpha 1 \mathrm{AG}$, Alpha 1-acid glycoprotein; AGP, antimicrobial growth 26 promoters; AHSG, $\alpha$-2-HS-glycoprotein; ApoF, apolipoprotein F, CLU, clusterin; Hp, 27 haptoglobin; FRAP, ferric reducing anti-oxidant power; HP, hibernation associated 28 protein; HP-27, hibernation associated plasma protein; OTC, oxytetracycline; PON1, 29 paraoxonase type-1; SAA, serum amyloid A

30

31 Keywords: Proteomics; Immunometabolism; Oxytetracycline; Antimicrobial growth 32 promoters; hibernation-associated plasma protein-27.

34 Total number of words including figure and table legends: 5916

35 


\section{Abstract}

37 The growth promoting effect of supplementing animal feed with antibiotics like tetracycline has traditionally been attributed to their antibiotic character. However, more evidence has been accumulated on their direct anti-inflammatory effect during the last two decades. Here we used a pig model to explore the systemic molecular effect of feed

41 supplementation with sub therapeutic levels of oxytetracycline (OTC) by analysis of 42 serum proteome changes. Results showed that OTC promoted growth, coinciding with a significant down regulation of different serum proteins related to inflammation, oxidation and lipid metabolism, confirming the anti-inflammatory mechanism of OTC.

45 Interestingly, apart from the classic acute phase reactants also down regulation was seen of a hibernation associated plasma protein (HP-27), which is to our knowledge the first description in pigs. Although the exact function in non-hibernators is unclear, down regulation of HP-27 could be consistent with increased appetite, which is possibly linked to the anti-inflammatory action of OTC. Given that pigs are good models for human medicine due to their genetic and physiologic resemblance, the present results

51 might also be used for rational intervention in human diseases in which inflammation

52 plays an important role such as obesity, type 2 diabetes and cardiovascular diseases. 
57 Immunometabolism is a relatively new field of study that investigates the interplay between the metabolic state and the immune system. Relatively recently, it was realized that obesity promotes inflammation, predisposing for a host of conditions such as cardiovascular disease $[1,2]$. Thought to be important in this process is the up regulation of the metabolic or postprandial inflammation the intensity of which is related to the energy value, glycemic index and lipid profile of food [3, 4]. Similar to humans with unhealthy habits, intensively produced animals such as chicken and pigs ingest large amounts of (high) energy feed, causing a state of inflammation too [5, 6]. The latter leads to a suboptimal feed utilization, muscle catabolism, decreased appetite, and consequently diminished growth [4]. Interestingly, the growth retardation in livestock used to be remedied by the use of the nowadays (in the EU) banned antimicrobial growth promoters (AGP) as feed additives. This suggested that they act as anti-inflammatory agents [5], although the conventional theory was that they worked by an antibiotic mechanism [7]. The latter is quite unlikely, mainly because of the low, sub therapeutic concentrations used, and a direct anti-inflammatory mechanism for growth promotion by AGP was proposed [5]. Among the most effective AGP were macrolides, shown to have also in humans direct anti-inflammatory effects on the immune system in lung disease [8]. Cyclines were recently shown to have clear anti-inflammatory effects on macrophages in vitro $[9,6]$, and in mice [10] and broilers [6], which in the latter was paralleled by growth promotion. There are also studies which point at a similar mechanism in pigs for cyclines [11].

78 Pigs are better experimental models for human research than chicken (or mice), due to their genetic, anatomic and physiologic resemblance, in particular concerning the gastrointestinal tract, and therefore more relevant for metabolic studies related to human 
81 immunometabolism [12]. Interestingly, antibiotic use in children has recently been

82 associated with increased body weight gain [13].

83 In the present study, we aimed at investigating the mechanism behind growth promotion

84 induced by a cycline in pigs. The serum proteome of pigs supplemented in feed with

85 oxytetracycline (OTC) was compared with that of unsupplemented pigs by 2DE DIGE

86 followed by MALDI-TOF/TOF. In addition to complete serum, fractions of the same

87 sera enriched for less abundant proteins by three different methods were analyzed in the same way. After validation, interpretation of results was performed through a bioinformatics systems biology analysis of the regulated proteins. Results were interpreted together with growth rates and clinical biochemistry parameters to define the 91 systemic effect of OTC supplementation in pigs.

2 Materials and methods

Animals

The experimental animal protocol was approved by the KU Leuven Ethics Committee

97 for Animal Experiments (protocol approval number P047/2008). Four week-old weaned piglets (Piètrain x Hypor) were housed in one stable, containing six $2 \mathrm{~m}^{2}$ pens, slatted floors with bedding, separated by bars, containing five piglets each. Piglets were weighed, and divided over the pens as equally as possible taking litter, weight, and sex

101 into account. Temperature was maintained at $26-27^{\circ} \mathrm{C}$, and piglets were kept at a $16 \mathrm{~h}$

102 light, 8 h dark cycle. Commercial starter and piglet meal diets (NV D2000 baby starter

103 and duo starter, Roeselare, Belgium) were offered to the animals from 28 to $47 \mathrm{~d}$ and

104 from 48 to $65 \mathrm{~d}$ of age, respectively, containing vitamins and minerals meeting or

105 exceeding National Research Council requirements. Feed and water were provided ad 
106 libitum throughout the experiment. The experimental period lasted 37 days in which

107 control piglets $(\mathrm{n}=15)$ received only the commercial diet, whereas treated animals

$108(\mathrm{n}=15)$ received a diet containing a commercial in-feed preparation of OTC (courtesy of

109 Huvepharma, Antwerp, Belgium) mixed in their feed with a final concentration of 200

110 ppm OTC. Piglets were weighed at days 0, 32 and 65 of the test period. During the

111 whole experiment the health status of the animals was monitored by visual and physical

112 examination. Two animals from control group and one animal from OTC group were

113 excluded from the study as they showed disease symptoms such as lameness, weight

114 loss and diarrhea. At test day 37, blood was collected by jugular venipuncture, and

115 allowed to clot for 1 hour at room temperature and was then centrifuged at $2000 \mathrm{x} g$ for

11615 min to obtain serum.

117

118 Acute phase protein determination

119 Serum levels of haptoglobin (Hp) and serum amyloid A (SAA) were used to determine

120 the general inflammatory status of the studied animals $(n=27)$. Haptoglobin was

121 measured with a colorimetric commercial kit (Tridelta Development Ltd, Kildare,

122 Ireland) according to the manufacturer's instructions, and SAA was determined with a

123 competitive ELISA assay previously developed and validated [14].

124

125 Sample material for proteomic analysis

126 Four serum samples of each group were randomly selected from control and OTC-

127 supplemented piglets. All of those specimens were subjected to one-dimensional SDS-

128 PAGE or 2DE DIGE, both in non-fractionated form and after a depletion/enrichment

129 step. The latter methods were used for reduction of major serum protein levels to 
130 facilitate uncovering differences in low abundant serum proteins. The following approaches were used:

Method 1: Albumin and IgG Depletion: A commercial kit (ProteaPrep Albumin and IgG

134 Depletion Sample Prep Kit; Protea, Morgantown, WV, USA) was used which employs 135 an non-antibody based ligand-ligand interaction for capture of serum albumin and IgG,

136 thus suitable for its use in non-human species. A volume of $10 \mu \mathrm{L}$ of serum was subjected to this depletion with the ProteaPrep Kit following the manufacturer's instructions. Besides the fall-through fraction containing the enriched material, also bound proteins were collected by elution with $400 \mu \mathrm{L} 0.1 \mathrm{M}$ glycine- $\mathrm{HCl} \mathrm{pH} 2.5$ (into tubes containing Tris buffer for $\mathrm{pH}$ adjustment), for further testing. Fall-through and bound proteins were kept at $-20^{\circ} \mathrm{C}$ until analysis.

Method 2: Protein enrichment on hexapeptide resin: the ProteoMiner protein enrichment system (Bio-Rad, Hercules, CA, USA) is based on the use of a combinatorial peptide binding library, which affinity-captures and amplifies the lowabundance proteome [15]. A total amount of $10 \mathrm{mg}$ (approx. $250 \mu \mathrm{L}$ of crude serum) of protein was treated according to the manufacturer's instructions. Both eluted and bound fractions were kept for analysis. The depleted serum (the initially bound fraction of this approach) was dialyzed against $100 \mathrm{mM}$ ammonium acetate $\mathrm{pH} 7$ in a PlusOne mini

$1501 \mathrm{kDa}$ cut-off dialysis kit (GE Healthcare, Munich, Germany), lyophilized and kept at $20^{\circ} \mathrm{C}$. Samples were later dissolved in IPG sample buffer [16] before further analysis. 
155 where the detergent rich phase is collected after raising the temperature to above the

156 cloud point. The enriched fraction is then diluted at a temperature below the cloud point

157 and concentrated by a TCA-acetone precipitation step. Pellets were dissolved in

158 appropriate sample buffer and kept at $-20^{\circ} \mathrm{C}$ until analysis. Starting material for this

159 method was $400 \mu \mathrm{L}$ of serum [17].

160 The protein concentration of fractions obtained by the above methods was determined

161 according to Bradford [18], and composition further analyzed as described below.

162

163 Proteome analysis

164 One-dimensional electrophoresis

165 A first screening and comparison of protein patterns of all different samples was

166 achieved by one-dimensional SDS-PAGE under reducing conditions on 140 x 140 x 1.5

167 mm gradient gels (10-15\% T, 2.7\% C) in a Hoefer SE 600 vertical electrophoresis

168 chamber (Hoefer scientific instruments, San Francisco, CA, USA). For serum samples,

$1690.5 \mu \mathrm{l}$ serum were applied per lane and protein bands stained with colloidal Coomassie

170 Blue G-250 (Novex, Invitrogen, Carlsbad, CA, USA) [19]. For the less concentrated

171 fractions from depletion/enrichment experiments, $2.5 \mu \mathrm{g}$ protein per lane were separated

172 in SDS-PAGE and subjected to silver staining [20]. Gels were scanned in a GE

173 Imagescanner III (GE Healthcare, Munich, Germany). All the images were digitalized

174 and analyzed by Image Studio Lite Software (Li-Cor Biosciences, Lincoln, NE, USA).

175

176 2DE DIGE

177 Differences in the serum proteome (or their enriched fractions) of control and OTC

178 piglets were evaluated by 2-DE DIGE. Samples were minimally labelled with CyDye

179 DIGE ${ }^{\text {TM }}$ fluorescent dyes according to the manufacturer's instructions (GE Healthcare, 
180 Munich, Germany). To exclude any effect of possible preferential labelling, dye swap

181 was performed. An IPG-DALT system was employed for 2DE, as described previously

182 [16]. This includes first-dimensional electrophoresis in IPG strips of $10 \mathrm{~cm}$ length

183 followed by SDS-PAGE as described above. Fluorescence images of the gels were

184 acquired on a Typhoon 9400 scanner (GE Healthcare, Munich, Germany). Image

185 analysis including spot detection, matching, normalization and quantification was

186 performed in four data sets. Spots of interest were identified after statistical analysis

187 (see below) and were excised from the gel after MS-compatible silver staining [16].

188

189

MALDI-TOF/TOF analyses

190 Sample preparation for mass spectrometry was performed as recently described [21].

191 Briefly, spots of interest were washed, destained, reduced and alkylated before in-gel

192 tryptic digestion (TrypsinGold, Mass Spectrometry Grade, Promega, Madison, WI,

193 USA). Extracted dried peptides were desalted and spotted prior to data acquisition on a

194 MALDI-TOF/TOF mass spectrometer (Ultraflex, Bruker Daltonics, Bremen, Germany)

195 in MS and MS/MS mode. Processed spectra were searched via an in-house Mascot

196 server (Matrix Science, Boston, MA) in the SwissProt/UniProt (Release 2014_06) or

197 EST_mammals (EST_120) database using the following search parameters: taxonomy:

198 sus scrofa; enzyme: trypsin/semi-trypsin, global modifications carbamidomethylation on

199 cysteine; variable modifications: Deamidated (NQ), Gln->pyro-Glu (N-term Q),

200 Oxidation (M); MS tolerance 100 ppm; MS/MS tolerance 1 Da; one missed cleavage

201 allowed. Identifications were considered statistically significant where $P<0.05$.

202

203

Interpretation of results through systems biology analysis 
204 Regulated proteins were listed as official gene names and subjected to systems biology

205 analysis using the "Set Distiller" module of GeneDecks website [22]. Because far more

206 human genes are annotated and more information in databases is available for humans

207 than for pigs, the human database was used for this functional analysis. Regulated

208 proteins were assigned to a specific pathway and retrieved when significant $(P<0.05)$.

209

210 Confirmatory methods

211 Protein regulation results from 2DE DIGE analysis were validated by running the

212 following additional tests, all with unfractionated serum:

213

214 Serum total IgG determination: Total IgG was quantified by using a pig-specific ELISA

215 test (USCN Life Sciences, Hubei, China), following the manufacturer's instructions.

216

217 Alpha 1-acid glycoprotein ( $\alpha 1 A G)$ measurement: The relative abundance of $\alpha 1 \mathrm{AG}$ was

218 determined by immunoblotting by using an in-house anti-bovine $\alpha 1 \mathrm{AG}$ rabbit

219 polyclonal antibody [23] with cross-reactivity with pig. Diluted serum samples (1/10) as

220 well as pure bovine $\alpha 1$ AGP (1 $1 \mu \mathrm{g})$ as positive control were separated on 4-12\% SDS-

221 PAGE minigels and blotted onto PVDF membrane. $\alpha 1 \mathrm{AG}$ was detected by a

222 biotinylated anti- $\alpha 1$ AG polyclonal antibody and an HRP-Streptavidin conjugate (Sigma,

223 Saint-Louis, MO, USA) with the help of a chromogen (4-chloro-1-naphthol) [20].

224 Subsequent total protein staining of the membrane with Coomassie brilliant blue R-250

225 served as a loading control. Both images were evaluated by scanning on a GE

226 Imagescanner III (GE Healthcare, Munich, Germany). All the images were digitalized

227 and analyzed by Image Studio Lite Software (Li-Cor Biosciences, Lincoln, NE, USA). 
228 For each lane, $\alpha 1 \mathrm{AG}$ band intensity values were normalized relative to the total protein 229 staining.

230

231 Biochemical measurement of paraoxonase type-1 (PON1) activity: PON1 was

232 quantified by determining the serum arylesterase activity using p-nitrophenyl acetate as

233 substrate in an automated clinical chemistry analyzer (Olympus AU2700, Olympus

234 Diagnostica, Tokyo, Japan) using a method adapted for pig serum samples [24]. Intra-

235 assay and inter-assay CV ranges were $0.5 \%$ to $1.5 \%$ and $4.8 \%$ to $5.5 \%$, respectively.

236 Serial dilution of 2 serum samples resulted in linear regression equations with

237 correlation coefficients close to $1(\mathrm{r}=0.998$ and 0.994$)$. The assay detection limit was

$238 \quad 0.15 \mathrm{U} / \mathrm{L}$.

239

240

Total serum antioxidant activity: The total antioxidant capacity of the serum samples

studied was determined through the ferric reducing anti-oxidant power (FRAP) assay as described elsewhere [25].

Statistical analysis

245 Statistical analysis of body weight measurements, acute phase protein determination and

246 validation results were performed by using the software program GraphPad Prism 5 for

247 Windows (GraphPad software, La Jolla, CA, USA). Differences in values of each

248 parameter described above were analyzed by two-tailed Student's t-tests, as

249 Kolmogorov-Smirnov test results indicated Gaussian distribution for all datasets. The

250 significance level was set at $P<0.05$ in all cases. DeCyder software Version 7.0 (GE

251 Healthcare, Munich, Germany) was used to identify differentially regulated spots

$252(P<0.05$; Fold-change \pm 1.3$)$ by two-way ANOVA. 


\section{Results}

255

Effect of OTC supplementation on weight gain and serum levels of acute phase proteins

256
Supplementation of animal feed with OTC at sub-therapeutic concentrations was associated with significantly higher weight gain of supplemented animals at the end of the experimental period compared to controls (Table 1A). OTC supplementation also resulted in numerically lower levels of serum haptoglobin and significantly lower levels of serum amyloid A (Table 1A).

\section{Enrichment of minor proteins}

Protein content and 1DE profile of initial serum samples were similar (CV\% of protein concentration was 13.05\%; Fig.1A). Banding patterns of enriched samples were distinct from serum, but typical for the respective method, and with little difference between individual samples of each group (for Proteominer and ProteaPrep treatment, see Fig.1B and 1C). Not enough material was obtained after Triton X-114 cloud point separation to additionally screen individual samples in SDS-PAGE (Fig.1D). Recoveries of enriched samples ranged between $0.1 \%$ of initial protein content for the Triton X-114 cloud point separation to $6.9 \%$ for Proteominer and $38 \%$ for ProteaPrep depletion systems. No differences in recovery were found between treatment groups.

\section{DE DIGE}

Combining results from all 2DE analyses, differences in spot intensity between gels from control and OTC-supplemented animals were identified in eighty-one matched different spots $(P<0.05)$. The Proteominer method yielded only 5 differentially regulated spots, all of which were identified as immunoglobulin heavy chains based on 
earlier observations. These were not subjected to MS analysis, and left out in the further analysis. For some of the regulated spots the amount of protein was insufficient to confidently identify the present proteins by MALDI-TOF/TOF. In total, thirteen different proteins were identified out of thirty-one spots (Table 2, Fig. 2, and Supplemental Table 1). Among those were two faint spots identified as $\alpha$-2-HSglycoprotein (AHSG) which were clearly smaller size breakdown products: in MS analysis for spot \#2259 only peptides of the amino-terminal part of the protein were found, for spot \#1376 only from the C-terminus (Fig. 2C). Analysis of the spots of the intact AHSG chain (spots \#328-331; Fig 2A) showed no differential regulation.

Clusterin (CLU) appears as two distinct spot chains in pig serum, but was in the present study too faint for positive MS identification. In the Triton X-114 cloud point separation method 2 CLU containing spots were identified (Fig. 2D), spot \#715 showed only peptides from the $\alpha$-chain, spot \#758 only from the $\beta$-chain. Both spot chains were regulated in a similar way, but with different degree of significance.

From all spots a single protein was identified except spot \#484 in which apart from PON1 also peptides from $\alpha 1 \mathrm{AG}$ were found.

Together, the two depletion methods identified three additional proteins not detected in whole serum (hibernation associated plasma protein (HP-27), PON1, and apolipoprotein F (ApoF)) as well as additional fragments of AHSG, $\alpha 1 \mathrm{AG}$, and Hp, with similar trends but not always with the same statistical significance.

\section{Systems biology analysis}

Proteins confidently identified were listed and analyzed in GeneDecks to detect significantly enriched pathways and GO biological functions (Table 3). Different 
302 pathways and GO terms related with the innate immune response, antioxidant activity

303 and lipid metabolism were found highly significant.

304

305

306

313 (Table 1B).

314 Serum Hp concentrations in the samples analyzed by 2DE DIGE were significantly

Additional analysis

Results from the additional analyses performed to validate the proteomics results are detailed in Table 1B.

OTC-supplemented pigs showed higher serum PON1 levels and total antioxidant activity as measured by FRAP (not statistically significant), and significantly lower levels of $\alpha 1 \mathrm{AG}$ as detected by western blot. Additional evaluation of PON1 activity has been undertaken because in spot \#484 also peptides of $\alpha 1$ AG had been found; activity measurement showed numerically higher levels of PON1 in the supplemented group lower in OTC-supplemented animals. No differences were found in the total IgG content.

\section{Discussion}

In the present study we aimed at the identification of the systemic immune and metabolic effects of OTC supplementation through the analysis of the pig serum proteome in treated and untreated animals. We used serum as its composition is known to reflect the physiological status of the individual [26], and proteomic analysis because it allows for the analysis of multiple proteins. However, blood-derived samples are difficult to analyze due to their high dynamic range (10-12 orders of magnitude) and because of the presence of a low number of highly abundant proteins [27]. To allow detection of concentration differences in low abundant serum proteins three different 
enrichment techniques were used. Due to the different underlying principles, the enrichment factor and resulting protein composition were highly dependent on the respective methods. This is well in line with previous reports, even though they partly used other prefractionation protocols [28]. All three methods in our experiments yielded enough protein to perform 2DE DIGE analysis. The Proteominer method yielded only spots of various immunoglobulin (Ig) chains. Similar differences concerning Ig chains are regularly found in many proteomics and transcriptomics studies, with unknown significance. Here, total immunoglobulin levels were not altered, as quantified by immunoassay.

Animals treated with OTC showed significant growth promotion and reduction in the acute phase protein SAA concentration compared to the control group. Proteomic analysis showed that growth promotion by OTC was accompanied with serum proteome changes largely consistent with down regulation of the inflammatory response. These responses are seen with the classic acute phase proteins, as well as with the HDL apolipoproteins CLU, ApoF and most likely also with PON1. Whereas the changes in the former two are unambiguous, in the spot of PON1 also peptides of $\alpha 1 \mathrm{AG}$ were found, raising questions about the origin of the up regulation. Because quantification based on MS was not possible, biochemical serum analysis of PON1 activity was performed, and showed a numerical up regulation, whereas $\alpha 1 \mathrm{AG}$ was significantly down regulated in serum by immunological analysis. Furthermore, $\alpha 1 \mathrm{AG}$ was also down regulated in another spot (\#515). Based on the above, we are fairly confident that PON1 (and not $\alpha 1 \mathrm{AG}$ ) is responsible for the up regulation found. Concerning the acute phase proteins, OTC-supplemented pigs showed down regulated spots of Hp and $\alpha 1$ AG. When analyzing all animals of the present experiment ( $\mathrm{n}=27$ ) by colorimetric assay, Hp level decrease in serum was marked, but not 
statistically significant. However, including only the animals from the 2DE DIGE experiment $(\mathrm{n}=8)$, changes determined in this assay were significant, thus confirming our proteomic results. A similar trend was observed when comparing the intensity of the Hp alpha chain protein bands in Figure 1, which further supporting that OTC-treated animals’ plasma contained lower levels of Hp. Significantly lower levels of serum $\alpha 1 \mathrm{AG}$ were found in OTC-supplemented pigs by 2DE DIGE, and subsequently confirmed by immuno-blotting. $\alpha 1 \mathrm{AG}$ is in most species a positive acute phase protein.

Recent evidences suggest that $\alpha 1 \mathrm{AG}$ is a negative acute phase protein in the pig during infection, whereas it has been observed that obese pigs form certain breeds show significantly higher serum levels of $\alpha 1 \mathrm{AG}$ compared to lean counterparts [29]. In humans, the levels of serum $\alpha 1 \mathrm{AG}$ rise with obesity, which is considered as a sign of overweight-associated low-grade inflammation [30]. Interestingly, levels of this protein have also been identified to be strongly inversely correlated with growth rate in swine in different studies, in the absence of confounding environmental, health and management factors [29,31]. It is therefore possible that different genetic backgrounds and inflammatory stimuli result in different responses of $\alpha 1 \mathrm{AG}$. In any case, the decrease in $\alpha 1 \mathrm{AG}$ levels in the present study paralleled those of SAA and Hp, and lower levels of positive acute phase proteins are known to positively correlate with daily weight gain and feed efficiency [32]. In contrast to Hp and $\alpha 1 \mathrm{AG}$, SAA was measurable only by ELISA in serum and could not be identified by 2DE DIGE. This could be due to the unique multimeric nature of pig SAA [33], causing it to disperse over the gel into multiple small and hence undetectable spots. Based on the down regulation of the positive acute phase proteins $\mathrm{Hp}, \alpha 1 \mathrm{AG}$, and SAA up regulation of the negative acute phase protein albumin was expected. No changes were observed in the main spot of albumin either in 1DE or 2DE gels, however, some smaller fragments of albumin were 
377 found in lower or higher concentration in OTC-supplemented animals, for which we

378 have no plausible explanation.

379 CLU, PON1 and ApoF are all HDL-related proteins which we found increased 380 in OTC-supplemented piglets. This also fits with an anti-inflammatory response because 381 HDL itself can be considered a negative acute phase reactant. However, this may not be 382 the only explanation, because no other HDL proteins were found to be regulated. CLU 383 (or apolipoprotein $\mathrm{J}$ ) is a secreted chaperone with anti-apoptotic, antioxidant and antiinflammatory functions that maintains fluid-epithelial interface homeostasis, thereby preventing the onset of inflammatory conditions [34]. Data relating CLU serum levels during obesity and systemic inflammation are conflicting: some studies claim upregulation and a correlation with inflammatory markers [35] whereas in others either no 388 clear relationship was found [36] or a down regulation was observed [37, 38]. A decrease in plasma CLU levels during weight reduction has been observed in humans [36] and dogs [39], which has been proposed to be an effect of the hypocaloric diet rather than being directly linked to weight loss [36]. Furthermore, CLU serum concentration is associated with those of other adipokines in relation to insulin

393 sensitivity/hyperglycemia and lipid metabolism, but not to body fat mass and inflammation [40]. Altogether, these data suggest that CLU might be an indicator of the body response towards diet-induced oxidative stress. Indeed, there is recent molecular evidence for the protective role of CLU against high-fat diet-induced insulin resistance 397 through the suppression of oxidative stress and inflammation [41]. The activities of 398 CLU and PON1 are closely related within the HDL particle, being responsible for the 399 protection of low density lipoproteins from oxidative modification [42]. PON1 is a 400 negative acute phase reactant in pigs [24]. PON1 is an antioxidant protein whose main 401 function appears to be the metabolization of toxic oxidized lipids of both low density 
402 lipoprotein (LDL) particles as well as HDL particles [43]. Yet, this protein also exerts

403 anti-inflammatory functions, such as directly suppressing macrophage pro-inflammatory

404 responses [44]. Down regulation of PON1 levels is associated with exacerbation of

405 obesity-related inflammation and oxidative stress [45]. We determined the enzymatic

406 activity of PON1 in serum, and the total antioxidant activity, and both were numerically

407 lower in control animals. Although not significant probably due to the low sample size,

408 it suggested a link between inflammation and lipid oxidation, since the exhaustion of the

409 enzymatic activity of PON1 has been related with the systemic low-grade inflammation

410 produced by oxidative stress in coronary heart disease patients [46]. The third up-

411 regulated apolipoprotein, ApoF, is also an atheroprotective protein, and involved in

412 cholesterol transport between lipoproteins, and their levels are positively associated

413 with a favorable proteomic signature for HDL [47].

414 It is concluded that the above findings on the acute phase proteins and HDL

415 apolipoproteins can be correlated in a straight forward manner with OTC-

416 supplementation causing a lower inflammatory state associated with decreased

417 oxidative stress. This is much less straight forward with AHSG and HP-27. AHSG

418 (also known as fetuin-A) is a pleiotropic molecule with metabolic and both anti- and

419 pro-inflammatory roles [48]. Both AHSG under- and over regulation have been

420 described to correlate with inflammation, the first being related with the acute phase

421 reaction [49] and the latter with the development of obesity-related disorders [50].

422 Concerning AHSG, lower levels were found only with of two AHSG breakdown

423 products, a $34 \mathrm{kDa}$ C-terminal fragment, and a $15 \mathrm{kDa} \mathrm{N}$-terminal fragment, but not

424 with intact AHSG. The biological role of these smaller products is unclear.

425 Interestingly, in the OTC-supplemented pigs HP-27 was down regulated.

426 Hibernation-associated plasma proteins (HP) were first identified in chipmunks as a 
427 group of proteins produced in the liver with fluctuating serum levels, depending on the

428 season. They appear at high concentration in the brain during hibernation [51].

429 However, they have been also identified in the plasma from non-hibernating mammals

430 such as squirrels [52] and cattle [53, 54]. To our knowledge, this is the first report of the

431 presence of HP proteins in pig serum. The exact function of HP proteins is unknown,

432 but structurally homologous proteins have been shown to contribute to energy

433 homeostasis, immunity, tumor cell apoptosis, and cell survival. It has been therefore

434 proposed that an increase in brain HP proteins during hibernation may protect

435

organisms from depressed metabolism and lethal diseases as observed in hibernators

436

[51]. The molecular mechanisms of the metabolic rate depression occurring during

437 hibernation include the suppression of energy-expensive cell functions, reprioritization

438 of ATP use, and enhanced expression of protective, anti-oxidative mechanisms [55].

439 This is accompanied by a lipid-based metabolism, transient insulin resistance and

440 hyperinsulinemia, but by none of the pathological features of metabolic syndrome [55].

441 In our case, the lower levels of HP-27 in OTC-supplemented animals might be

442 interpreted as indicative of a metabolic switch by OTC to an energy-saving, antioxidant

443 phenotype, similar to what happens in hibernators. Furthermore, pig HP-27 may depress

444 appetite, as has been suggested for bovine HPs injected intracerebroventricularly in

445 mice. Although the latter results have to be interpreted with caution [54], the lower HP-

44627 serum levels found in the OTC group here could be consistent with the observed

447 increased appetite in OTC treated animals [5, 6]. Pro-inflammatory cytokines are

448 thought to be responsible for (in)appetence, but the present results may be indicative of

449 a new alternate pathway. However, it is entirely unclear whether or not inflammation

450 and HP-27 abundance are linked. Further research should be performed to confirm the

451 precise role of this relatively unknown protein. 
453 In conclusion, in feed OTC supplementation of weaned piglets produced changes in the 454 serum proteome largely consistent with an anti-inflammatory mechanism for OTC. 455 These changes reflected a metabolic change to an energy-saving, growth-promoting 456 phenotype associated with enhanced protection against lipid oxidation. The obtained 457 results support the anti-inflammatory hypothesis as the main mechanism of action of 458 AGP. The latter may also offer a plausible mechanism for the hitherto unexplained 459 growth promotion by antibiotics observed in children [56, 13]. Finally, given that pigs are good models for humans for their great genetic and physiologic resemblance, the

461 present results might also be relevant for human immunometabolic diseases such as 462 obesity, type 2 diabetes and cardiovascular diseases [57].

463

464 Acknowledgements

465

J.J. Cerón and K. De Backer are acknowledged for their help during results validation. Lotte Svare Holck is thanked for technical assistance with the Triton X-114 cloud point separation method. L. Soler acknowledges financial support by the Martín Alonso 468 Escudero Foundation, Spain.

469

470

All authors declare no conflict of interest.

471

472

4735 References

474

475 [1] Hotamisligil, G.S., Nature 2006, 444, 860-867.

476 [2] Mathis, D., Shoelson, S.E., Nat. Rev. Immunol. 2011, 11, 81. 
477 [3] Margioris, A.N., Curr. Opin. Clin. Nutr. Metab. Care 2009, 12, 129-137.

478 [4] Niewold, T.A., in: Garnsworthy P.C., Wiseman J. (Eds.) Recent Advances in Animal 479 Nutrition, Nottingham University Press, Nottingham, 2010. pp. 191-205.

480 [5] Niewold, T.A., Poult. Sci. 2007, 86, 605-609.

481 [6] Khadem, A., Soler, L., Everaert, N., Niewold, T.A., Br. J. Nutr. 2014, 112, 1110$482 \quad 1118$.

483 [7] Dibner, J.J., Richards, J.D., Poult. Sci. 2005, 84, 634-643.

484 [8] Hoyt, J.C., Robbins, R.A., FEMS Microbiol. Lett. 2001, 205, 1-7.

485 [9] Dunston, C.R., Griffiths, H.R., Lambert, P.A., Staddon, S., Vernallis, A.B., $486 \quad$ Proteomics 2011, 11, 42-51.

487 [10] Costa, E., Uwiera, R.R., Kastelic, J.P., Selinger, L.B., Inglis, G.D., Gut Pathog. $488 \quad 2011,3,14$.

489 [11] Bosi, P., Merialdi, G., Scandurra, S., Messori, S., Bardasi, L., Nisi, I., Russo, D., 490 Casini, L., Trevisi, P., J. Anim. Sci. 2011, 89, 4043-4053.

491 [12] Gonzalez, L.M., Moeser, A.J., Blikslager, A.T., Transl. Res. 2015, 166, 12-27.

492 [13] Schwartz, B.S., Pollak, J., Bailey-Davis, L., Hirsch, A.G., Cosgrove, S.E., Nau, C., 493 Kress, A.M., Glass, T.A., Bandeen-Roche, K., Int. J. Obes. (Lond.) 2015, doi: 494 10.1038/ijo.2015.218. [Epub ahead of print]

495

[14] Soler, L., Gutiérrez, A., Martínez-Subiela, S., Ceron, J.J., Vet. J. 2011, 190, e7-11.

496 [15] Boschetti, E., Righetti, P.G., J. Prot. 2008, 71, 255-264.

497 [16] Miller, I., Methods Mol. Biol. 2012, 854, 373-396.

498 [17] Jessen, F., Wulff, T., Anal. Biochem. 2015, 485, 11-17.

499 [18] Bradford, M.M., Anal. Biochem. 1976, 72, 248-254.

500 [19] Miller, I., Friedlein, A., Tsangaris, G., Maris, A., Fountoulakis, M., Gemeiner, M., $501 \quad$ Proteomics 2004, 4, 3227-3234. 
502 [20] Miller, I., Gemeiner, M., Electrophoresis 1992, 13, 450-453.

503 [21] Marco-Ramell, A., Hummel, K., Razzazi-Fazeli, E., Bassols, A., Miller, I., $504 \quad$ Electrophoresis 2015, 36, 543-551.

505 [22] Stelzer, G., Inger, A., Olender, T., Iny-Stein, T., Dalah, I., Harel, A., Safran, M., $506 \quad$ Lancet, D., OMICS 2009, 13, 477-487.

507 [23] Ceciliani, F., Pocacqua., V, Miranda-Ribera, A., Bronzo, V., Lecchi, C., Sartorelli, $508 \quad$ P., Vet. Immunol. Immunopathol. 2007, 116, 145-152.

509 [24] Escribano, D., Tvarijonaviciute, A., Tecles, F., Cerón J.J., Vet. Immunol. $510 \quad$ Immunopathol. 2015, 163, 210-215.

511 [25] Benzie, I.F., Strain, J.J., Anal. Biochem. 1996, 239, 70-76.

512 [26] Miller, I., Wait, R., Sipos, W., Gemeiner, M., Res. Vet. Sci. 2009, 86, 362-367.

513 [27] Anderson, N.L., Anderson, N.G., Mol. Cell. Proteomics 2002, 1, 845-867.

514 [28] Fernández, C., Santos, H.M., Ruíz-Romero, C., Blanco, F.J., Capelo-Martínez, J.L., $515 \quad$ Electrophoresis 2011, 32, 2966-2974.

516 [29] Rødgaard T, Skovgaard K, Stagsted J, Heegaard PM. Cell Reprogram. 2013 517 Jun;15(3):185-94.

518 [30] Maachi M1, Piéroni L, Bruckert E, Jardel C, Fellahi S, Hainque B, Capeau J, 519 Bastard JP. Int J Obes Relat Metab Disord. 2004 Aug;28(8):993-7.

520 [31] Heegaard, P.M., Miller, I., Sorensen, N.S., Soerensen, K.E., Skovgaard, K., PLoS $521 \quad$ One 2013, 8, e68110.

522 [32] Clapperton, M., Diack, A.B., Matika, O., Glass, E.J., Gladney, C.D., Mellencamp, 523 M.A., Hoste, A., Bishop, S.C., Genet. Sel. Evol. 2009, 30, 41:54.

524 [33] Soler, L., Molenaar, A., Merola, N., Eckersall, P., Gutiérrez, A., Cerón, J., Mulero, 525 V., Niewold, T., J. Theor. Biol. 2013, 317, 119-125.

526 [34] Jones, S.E., Jomary, C., Int. J. Biochem. Cell Biol. 2002, 34: 427-431. 
[35] Won, J.C., Park, C.Y., Oh, S.W., Lee, E.S., Youn, B.S., Kim, M.S., PLoS One 2014, 9, e103351.

[36] Arnold, T., Brandlhofer, S., Vrtikapa, K., Stangl, H., Hermann, M., Zwiauer, K., Mangge, H., Karwautz, A., Huemer, J., Koller, D., Schneider, W.J., Strobl, W., Pediatr. Res. 2011, 69, 237-242.

[37] Hoofnagle, A.N., Wu, M., Gosmanova, A.K., Becker, J.O., Wijsman, E.M., Brunzell, J.D., Kahn, S.E., Knopp, R.H., Lyons, T.J., Heinecke, J.W., Arterioscler. Thromb. Vasc. Biol. 2010, 30, 2528-2534.

535

[38] Martos-Moreno, G.Á., Sackmann-Sala, L., Barrios, V., Berrymann, D.E., Okada, S., Argente, J., and Kopchick, J.J., Int J Pediatr. Endocrinol. 2014, 2014, 9.

[39] Tvarijonaviciute, A., Gutiérrez, A.M., Miller, I., Razzazi-Fazeli, E., Tecles, F., Ceron, J.J., Domest. Anim. Endocrinol. 2012, 43, 271-277.

539

[40] Flehmig, G., Scholz, M., Klöting, N., Fasshauer, M., Tönjes, A., Stumvoll, M., Youn, B.S., Blüher, M., PLoS One 2014, 9, e99785.

[40] Kwon, M.J., Ju, T.J., Heo, J.Y., Kim, Y.W., Kim, J.Y., Won, K.C., Kim, J.R., Bae, Y.K., Park, I.S., Min, B.H., Lee, I.K., Park, S.Y., Endocrinol. 2014, 155, 20892101.

545

[42] Kujiraoka, T., Hattori, H., Miwa, Y., Ishihara, M., Ueno, T., Ishii, J., Tsuji, M., 545 Iwasaki, T., Sasaguri, Y., Fujioka, T., Saito, S., Tsushima, M., Maruyama, T., Miller, I.P., Miller, N.E., Egashira, T., 2006. J. Atheroscler. Thromb. 2006, 13, 314322.

548 [43] Costa, L.G., Vitalone, A., Cole, T.B., Furlong, C.E., Biochem. Pharmacol. 2005, 549 69, 541-550.

550

[44] Aharoni, S., Aviram, M., Fuhrman, B., Atheroscler. 2013, 228, 353-361. 
[45] Krzystek-Korpacka, M., Patryn, E., Hotowy, K., Czapińska, E., Majda, J., Kustrzeba-Wójcicka, I., Noczyńska, A., Gamian, A., Adv. Clin. Exp. Med. 2013, 22, 229-236.

[46] Kotur-Stevuljevic, J., Spasic, S., Jelic-Ivanovic, Z., Spasojevic-Kalimanovska, V., Stefanovic, A., Vujovic, A., Memon, L., Kalimanovska-Ostric, D., Clin. Biochem. 2008, 41, 1067-1073.

[47] Lagor, W.R., Fields, D.W., Khetarpal, S.A., Kumaravel, A., Lin, W., Weintraub, N., Wu, K., Hamm-Alvarez, S.F., Drazul-Schrader, D., de la Llera-Moya, M., Rothblat, G.H., Rader, D.J., PLoS One 2012, 7, e31616.

[48] Arnaud, P., and Kalabay, L., Diabetes Metab. Res. Rev. 2002, 18, 311-314.

[49] Lebreton, J.P., Joisel, F., Raoult, J.P., Lannuzel, B., Rogez, J.P., Humbert, G., J. Clin. Invest. 1979, 64, 1118-1129.

[50] Trepanowski, J.F., Mey, J., Varady, K.A., Int. J. Obes. (Lond.) 2015, 39, 734-741.

[51] Kondo, N., Cold Spring Harb. Symp. Quant. Biol. 2007, 72, 607-613.

[52] Ono, M., Kojima-Kawagoe, M., Kondo, N., Shiba, T., Takamatsu, N., Gene 2003, 302, 193-199.

[53] Wait, R., Miller, I., Eberini, I., Cairoli, F., Veronesi, C., Battocchio, M., Gemeiner, M., Gianazza, E., Electrophoresis 2002, 23: 3418-3427.

[54] Seldin, M.M., Byerly, M.S., Petersen, P.S., Swanson, R., Balkema-Buschmann, A., Groschup, M.H., Wong, G.W., J. Exp. Biol. 2014, 217, 2667-2679.

[55] Martin, S.L., Diab. Vasc. Dis. Res. 2008, 5, 76-81.

[56] Gough, E.K., Moodie, E.E., Prendergast, A.J., Johnson, S.M., Humphrey, J.H., Stoltzfus, R.J., Walker, A.S., Trehan, I., Gibb, D.M., Goto, R., Tahan, S., de Morais, M.B., Manges, A.R., Brit. Med. J. 2014, 348, g2267.

[57] Esser, N., Paquot, N., Scheen, A.J., Expert Opin. Investig. Drugs 2014, 25, 1-25. 
578 A. Weight gain and acute phase protein of pigs.

579

B. Validation of selected factors identified by proteomic analysis by other methods.

580

Table 2. Proteins differentially regulated in OTC-treated pigs' serum and identified by MALDI-TOF/TOF mass spectrometry. Indicated by asterisk $\left(^{*}\right)$ is spot \#715, included (near significant) to complete the information about clusterin spot \#758, as both spots belong to different clusterin chains ( $\alpha$, and $\beta$ respectively).

585

Table 3. GeneDecks pathway analysis of proteins differentially regulated in OTCtreated animals.

588

589

590

\section{Legends to figures}

591

592

Figure 1. SDS-PAGE protein profiles of serum samples before (A, Coomassie staining) and after (B-D, silver-staining) depletion treatments.

594

(A) Protein pattern of some whole serum samples from control and OTC-treated animals is shown. In B and C the protein profile of fractions (bound and eluted) obtained after Proteominer and ProteaPrep treatment is shown, respectively. Asterisks indicate samples later analyzed by 2DE DIGE. In D the protein profile before (1) and after $(2,3)$ Triton $\mathrm{X}-114$ cloud point separation of two control pig serum samples is shown.

600

601 Figure 2. 2DE of serum samples and depleted fractions 
602 Representative 2DE gel images of whole serum proteins (A) and after

603 enrichment/depletion treatment with Proteominer (B), ProteaPrep (C) and Triton X-114

604 cloud point separation (D). Protein spots significantly regulated after OTC treatment

605 (see Table 2) are indicated. Italic numbers (A; spots \#328-331) represented unregulated

606 intact AHSG chains. Brackets indicate the position of the series of related CLU chains

607 (D).

608

609 Supplemental table 1: Peptide table of mass spectrometric protein identification (Carb:

610 Carbamidomethylation on cysteine, Ox: Oxidation on methionine) 